\title{
Paroxysmal hemicrania associated to carotid artery dissection: a case report
}

\author{
Felipe Araújo Andrade de Oliveira (iD) , Pedro Augusto Sampaio Rocha-Filho \\ Universidade Federal de Pernambuco, Recife, Brazil
}

$\triangle$

Felipe Araújo Andrade de Oliveira

Abraham Lincoln St, 141, Recife,

Pernambuco, Brazil

felipe.oliveira1983@gmail.com

Edited by

Mario Fernando Prieto Peres

Marcelo Moraes Valença

\section{Keywords:}

Paroxysmal hemicranias

Carotid dissection

Secondary headaches

Trigeminal Autonomic Cephalalgias

Indomethacin

Pain

\begin{abstract}
There are numerous case reports relating trigeminal autonomic cephalalgias to structural injuries. However there is no description of the association between paroxysmal hemicrania and carotid artery dissection. We describe a previously healthy 63-year-old male presented with the onset of severe, throbbing pain in the right frontal region, lasting between 10 and 30 minutes, with a frequency of approximately two to three attacks per day, which began two days before seeking medical care. Pain was associated with ipsilateral tearing, semiptosis and nasal congestion. A cervical arterial magnetic resonance angiography demonstrated left carotid artery dissection in the $\mathrm{C} 1 / \mathrm{C} 2$ segment of the left internal carotid artery. The patient became asymptomatic after indomethacin use. We conclude that The possibility of investigating carotid dissection should be considered in patients with paroxysmal hemicrania.
\end{abstract}




\section{Introduction}

D aroxysmal hemicrania is a disorder characterized by severe, unilateral headache, lasting between two to thirty minutes, with an orbital, supraorbital and/or temporal localization, associated with ipsilateral autonomic symptoms. A marked response to indomethacin is essential for diagnosis. ${ }^{1}$

Although trigeminal autonomic cephalalgias are classified as primary headaches' ${ }^{1}$, there are numerous case reports relating such headaches to structural injuries. ${ }^{2 \cdot 4}$ To the best of our knowledge, there is no description of the association between paroxysmal hemicrania and carotid artery dissection. Herein, we describe one case that may demonstrate this association.

\section{Case report}

A previously healthy 63-year-old white man presented with the onset of severe, throbbing pain in the right frontal region, lasting between 10 and 30 minutes, with a frequency of approximately two to three attacks per day, which began two days before seeking medical care. Pain was associated with ipsilateral tearing, semiptosis and nasal congestion. There was no photophobia, phonophobia, nausea or vomiting associated with pain. There was not any history of head or neck trauma. Physical and neurological examination was normal. The physical examination was not suggestive of other disorders such as Marfan or Ehlers-Danlos syndrome.

Magnetic resonance imaging and intracranial magnetic resonance angiography were normal. A cervical arterial magnetic resonance angiography demonstrated left carotid artery dissection in the $\mathrm{Cl} / \mathrm{C} 2$ segment (Figure $1 \mathrm{~A}$ and B). This exam did not find any specific cause for the carotid dissection.

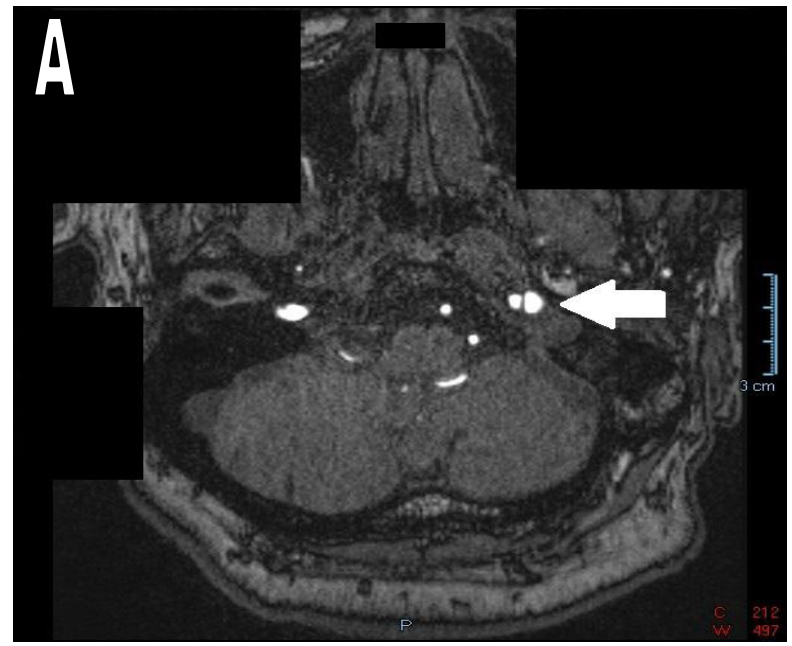

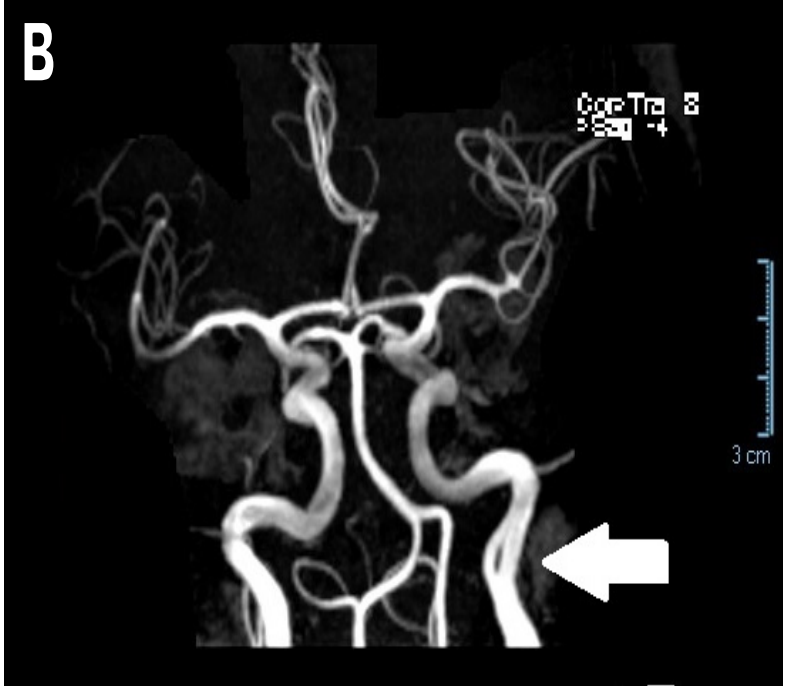

Figure 1. A and B) Cervical arterial resonance angiography demonstrates dissection in the left carotid artery in the $\mathrm{C} 1 / \mathrm{C} 2$ segment.

For the treatment of arterial dissection, acetylsalicylic acid and atorvastatin were used. For the treatment of headache, indomethacin (50 mg every 8 hours) was initiated orally, with a significant pain response in only 3 days. The patient became asymptomatic. He took indomethacin for 15 days.

He has had no headaches for three years and has not had any stroke. He still uses acetylsalicylic acid and atorvastatin. He made follows-up magnetic resonance angiography every six months. The last magnetic resonance angiography was performed three years after the headache and the dissection is stable.

The patient had given his written consent for the case report.

\section{Comments}

Our patient had no signs or symptoms on the same side as the dissection. Between 26 to $36 \%$ of patients who have carotid dissection have no head, face or neck pain ${ }^{5}$ and $25.5 \%$ of these patients have no local signs or symptoms. ${ }^{6}$

There are descriptions of headache compatible with paroxysmal hemicrania associated with intracranial secondary lesions such as expansive lesions in the sella turcica, pituitary apoplexy, intraparenchymal pontomesencephalic hemorrhage, type I Chiari malformation and giant cell arteritis. ${ }^{2,7.11}$ 
Our patient fulfilled the criteria for paroxysmal hemicranias, except for the frequency of pain, which was less than five attacks per day, on most days. We cannot completely rule out the possibility that the association between headache and dissection was a coincidence. However, there was a temporal relationship between the dissection and headache and, the patient had no previous headache. This reinforces a cause and effect relationship between dissection and headache. There was also a temporal relationship between the use of indomethacin and the patient's improvement. We cannot be certain whether this response was due to the use of the medication or to the natural history of the disease.

We did not find other reports about the association between paroxysmal hemicrania and carotid dissection. However, there were an association between carotid dissection and cluster headache $e^{2}$ and between carotid dissection and hemicrania continua. ${ }^{12}$ In all these reported cases of cluster headache and hemicranina continua, the dissection was ipsilateral to pain. ${ }^{2,12}$

Our patient presented with contralateral headache regarding the side of the arterial dissection. The pathophysiology of autonomic trigeminal headaches involves abnormalities of the hypothalamic function, trigeminal-autonomic reflex disinhibition, cranial and trigeminovascular autonomic activation. ${ }^{13,} 14$ In cluster headaches, studies with positron emission tomography and functional magnetic resonance demonstrate activation of the ipsilateral posterior hypothalamus during the pain attack. ${ }^{14}$ In the paroxysmal hemicrania, activation occurs of the contralateral posterior hypothalamus and the contralateral ventral midbrain to the pain during the attacks. ${ }^{14}$ This may justify the fact that the dissection was contralateral to our patient's headache since it would be ipsilateral to the activated hypothalamus. Another case of paroxysmal hemicrania associated with intraparenchymal hemorrhage also presented contralateral headache to the lesion, corroborating this explanation. ${ }^{7}$

\section{Conclusion}

In conclusion, in patients with paroxysmal hemicrania, the possibility of investigating carotid dissection should be considered.

\section{Key points}

- Carotid dissection may present as paroxysmal hemicrania.
- Paroxysmal hemicrania can also be a secondary headache.

- The headache presentation can be contralateral to the lesion.

Conflict of interest: The authors declare that there is no conflict of interest.

Financial support: There was no financial support.

\section{Author's contributions:}

Felipe Araújo Andrade de Oliveira: Conceptualization, Data curation, Writing original draft

Pedro Augusto Sampaio Rocha-Filho: Supervision, Writing review and editing

Felipe Oliveira

https://orcid.org/0000-0002-9583-3165

Pedro Augusto Sampaio Rocha-Filho

https://orcid.org/0000-0001-5725-2637

\section{References}

1. Headache Classification Committee of the International Headache Society (IHS) The International Classification of Headache Disorders, 3rd edition. Cephalalgia 2018;38(1):1-211 Doi: https://www.doi. org/10.1177/0333102417738202

2. Cittadini $E$ and Matharu MS. Symptomatic trigeminal autonomic cephalalgias. Neurologist 2009; 15(6):305312 Doi: https://www.doi.org/10.1097/ NRL.0b013e3181ad8d67

3. De Coo IF, Wilbrink LA and Haan J. Symptomatic Trigeminal Autonomic Cephalalgias. Curr Pain Headache $\operatorname{Rep} 2015 ; 19(8): 39$ Doi: https://www.doi. org/10.1007/s $11916-015-0514-z$

4. Chowdhury D. Secondary (Symptomatic) Trigeminal Autonomic Cephalalgia. Ann Indian Acad Neurol 2018;21(Suppl 1):S57-s69 Doi: https://www.doi. org/10.4103/aian.AIAN_16_18

5. Bazan R, Almeida LA, Rocha FC, Raffin $C N$ and Fonseca RG. Headache secondary to haemorrhagic stroke resembling paroxysmal hemicrania. Arq Neuropsiquiatr 2008;66(3b):761-762

6. Gatzonis S, Mitsikostas DD, llias A, Zournas CH and Papageorgiou $C$. Two more secondary headaches mimicking chronic paroxysmal hemicrania. Is this the exception or the rule? Headache 1996;36(8):51 1-513

7. Monzillo P, Nemoto P, Costa A and Rocha AJ. Paroxysmal hemicrania-tic and Chiari I malformation: an unusual association. Cephalalgia 2007;27(12): 14081412 Doi: https://www.doi.org/10.1111/j.14682982.2007.01362.x 
8. Beams JL and Rozen TD. Paroxysmal hemicrania as the clinical presentation of giant cell arteritis. Clin Pract 2011;1(4):e1 11 Doi: https://www.doi.org/10.4081/ cp.2011.e111

9. Grangeon L, Moscatelli L, Zanin A, Rouille A, Maltete $D$ and Guegan-Massardier E. Indomethacin-Responsive Paroxysmal Hemicrania in an Elderly Man: An Unusual Presentation of Pituitary Apoplexy. Headache 2017;57(10):1624-1626 Doi: https://www.doi. org/10.1111/head.13201

10. Matharu M and May A. Functional and structural neuroimaging in trigeminal autonomic cephalalgias. Curr Pain Headache Rep 2008; 12(2): 132-137

11. Obermann M, Holle D and Nagel S. Functional Neuroimaging in Trigeminal Autonomic Cephalalgias.
Ann Indian Acad Neurol. 2018;21(Suppl 1):S51-s56 Doi: https://www.doi.org/10.4103/aian. AIAN_357_17

12. Brilla R, Pawlowski M and Evers S. Hemicrania continua in carotid artery dissection - symptomatic cases or linked pathophysiology? Cephalalgia 2018;38(2):402-405 Doi: https://www.doi. org/10.1177/0333102416686346

13. Prakash $S$ and Patell R. Paroxysmal hemicrania: an update. Curr Pain Headache Rep 2014; 18(4):407 Doi: https://www. doi.org/10.1007/s $11916-014-0407-6$

14. Matharu MS, Cohen AS, Frackowiak RS and Goadsby PJ. Posterior hypothalamic activation in paroxysmal hemicrania. Ann Neurol 2006;59(3):535-545 Doi: https://www.doi.org/10.1002/ana.20763 